\title{
Bowel perforation presenting with acute abdominal pain and subcutaneous emphysema in a 14-year-old girl with an abandoned distal peritoneal shunt catheter: case report
}

\author{
Gerald J. Riccardello Jr., ME, ${ }^{1}$ Luke K. Barr, MD, ${ }^{2}$ and Luigi Bassani, MD \\ ${ }^{1}$ Rutgers New Jersey Medical School and ${ }^{3}$ Department of Neurological Surgery, Rutgers New Jersey Medical School, Newark, \\ New Jersey; and 2Department of Neurology, University of North Carolina, Chapel Hill, North Carolina \\ The authors report the case of 14-year-old girl with a history of myelomeningocele and previously shunt-treated hydro- \\ cephalus who presented with right-sided abdominal pain and subcutaneous emphysema that developed over a 1-week \\ period. A CT scan of the patient's abdomen revealed a retained distal ventriculoperitoneal (VP) catheter with air tracking \\ from the catheter to the upper chest wall. Given the high suspicion of the catheter being intraluminal, an exploratory lapa- \\ rotomy was performed and revealed multiple jejunal perforations. The patient required a partial small-bowel resection \\ and reanastomosis for complete removal of the retained catheter. Six other similar cases of bowel perforation occurring \\ in patients with abandoned VP and subdural-peritoneal shunts have been reported. The authors analyzed these cases \\ with regard to age of presentation, symptomatic presentation, management, morbidity, and mortality. While there was \\ $0 \%$ mortality associated with bowel perforation secondary to a retained distal VP catheter, the morbidity was significantly \\ high and included peritonitis and small bowel resection. \\ http://thejns.org/doi/abs/10.3171/2016.3.PEDS15572
}

KEY WORDS ventriculoperitoneal shunt; bowel perforation; retained shunt catheter; abandoned shunt catheter; redundant shunt catheter; hydrocephalus

$\mathrm{B}$ OWEL perforation is a documented complication of ventriculoperitoneal (VP) shunts, occurring in approximately $0.1 \%-1 \%$ of shunt-treated hydrocephalus patients. ${ }^{9}$ Occurring even more rarely are intraabdominal complications from abandoned distal peritoneal catheters. We present the case of a 14-year-old girl with a retained peritoneal catheter following partial removal 1 year earlier for a CSF infection. The patient presented with acute abdominal pain and subcutaneous emphysema along the right chest wall tracking rostral from the catheter in the abdominal subcutaneous tissue. We reviewed the literature and found only 6 other cases pertaining to bowel perforation secondary to abandoned abdominal catheters. In our review, we sought to evaluate the morbidity associated with these rare, albeit recognized, occurrences.

\section{Case Report}

This 14-year-old girl had undergone repair of a myelomeningocele and placement of a VP shunt for hydrocepha- lus at birth. She was noted to have a short distal catheter on routine imaging at age 7 years and underwent distal catheter lengthening. A metal connector was placed at the distal end of the tubing within the abdomen and connected to longer distal peritoneal tubing. At 13 years of age, the patient presented with an acute infection. The proximal catheters were removed, and an external ventricular drain was placed. The distal catheter snapped at the metal connector and the distal tubing was abandoned within the subcutaneous tissue of the abdomen and peritoneum. The patient was weaned of her CSF diversion and was discharged from the hospital without the need for a CSF shunt.

One year later, the patient presented to the emergency department with complaints of abdominal pain and diarrhea. The abdominal ultrasound and radiography studies were negative for pseudocyst or change in position of the catheter. The patient returned to the emergency department with increased abdominal pain 2 weeks later. She was at neurological baseline and her abdomen was soft without peritoneal signs, but with tenderness over the surgi-

ABBREVIATIONS VP = ventriculoperitoneal

SUBMITTED September 27, 2015. ACCEPTED March 14, 2016.

INCLUDE WHEN CITING Published online May 6, 2016; DOI: 10.3171/2016.3.PEDS15572. 
cal wound. Her complete blood count and comprehensive metabolic panel were within normal limits. Her erythrocyte sedimentation rate was slightly elevated $(43 \mathrm{~mm} / \mathrm{hr}$, normal range $0-20 \mathrm{~mm} / \mathrm{hr}$ ) and her C-reactive protein was elevated $(17 \mathrm{mg} / \mathrm{L}$, normal range $0-5 \mathrm{mg} / \mathrm{L})$. Computed tomography of the abdomen revealed the retained distal catheter and subcutaneous air tracking cephalad from the catheter to the right upper chest wall (Fig. 1).

The patient was taken emergently to the operating room by the neurosurgery and general surgery services for an exploratory laparoscopy, which was converted to a laparotomy. The distal end of the peritoneal catheter was looped through the jejunum (Fig. 2). Attempts were made to remove the catheter, but ultimately the penetrated segment of bowel required resection and reanastomosis. Postoperatively, the patient did well and was discharged home.

\section{Discussion}

Intraabdominal complications of intact VP shunts are well documented and include inguinal herniation, hydrocele, ascites, ileus, peritoneal infection, volvulus and intussusception, nonenteric viscous perforation, and intestinal perforation. ${ }^{4}$ Bowel perforation from intact VP shunt catheters, while rare with an incidence of $0.1 \%-1 \%,{ }^{9}$ carries a mortality rate of $15 \%$ and is well documented in the literature. ${ }^{6}$ Even rarer, however, are cases of abdominal complications from abandoned distal peritoneal catheters from previously removed VP shunts. The morbidity and mortality of such cases is not well established.

A literature review revealed 5 cases of intestinal perforation secondary to abandoned peritoneal shunt catheters $^{1,2,4,5,8}$ and 1 reported case of intestinal perforation secondary to abandoned subdural-peritoneal shunt tubing ${ }^{3}$ (Table 1). Of 6 of the 7 cases, $83 \%$ of the patients had VP shunts placed when they were younger than 18 years, and $57 \%$ (4 of 7) were diagnosed with perforation before the
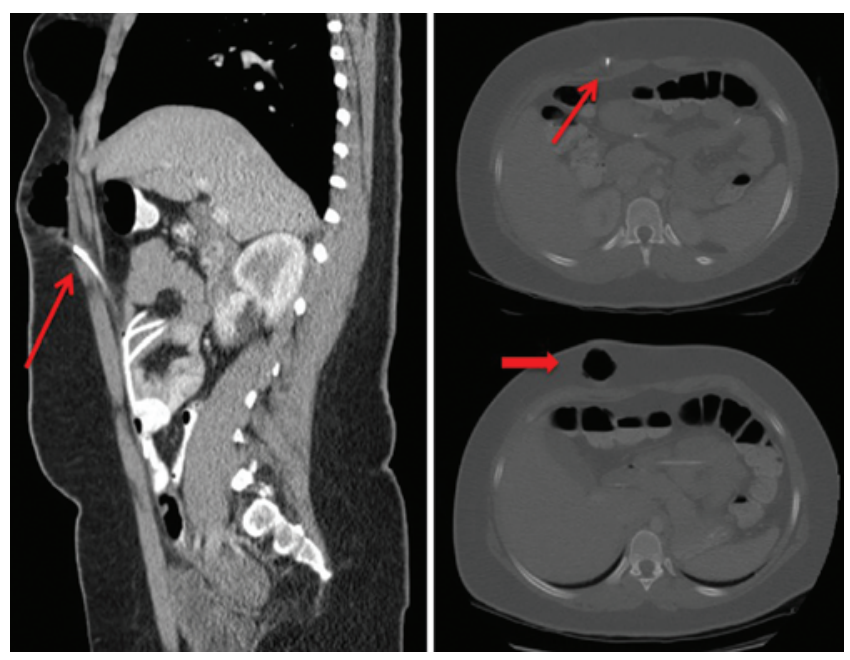

FIG. 1. Sagittal (left) and axial (right) CT scans obtained of the abdomen, revealing the retained distal peritoneal catheter within the lumen of the small bowel and the proximal tip extending into the abdominal subcutaneous tissue (thin arrow). Air tracking cephalad from the subcutaneous catheter to the right breast can easily be seen on both sequences (thick arrow). Figure is available in color online only.

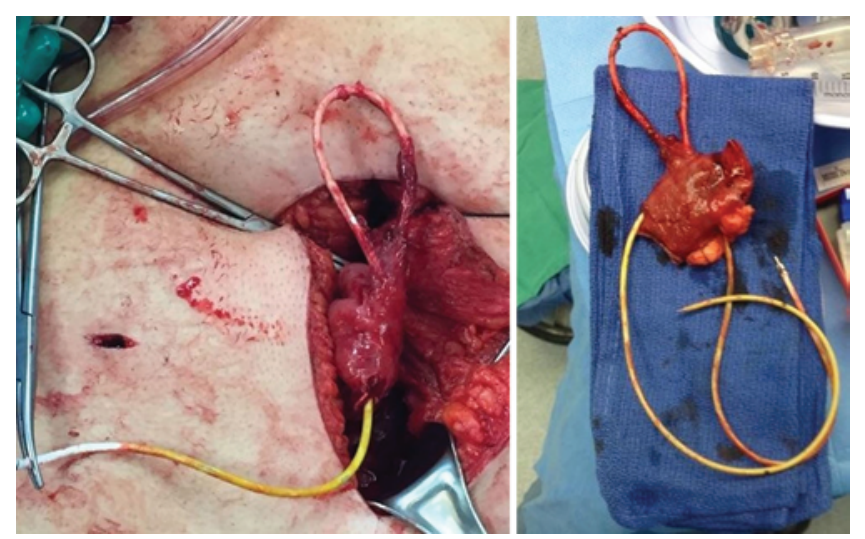

FIG. 2. Intraoperative finding of the jejunum with the retained distal catheter looping through the bowel with multiple sites of fibrosed entry and exit. Left: Preresection. Right: Postresection. Figure is available in color online only.

age of 18 years. The increased incidence in children has been attributed to weaker intestinal musculature and stronger peristaltic activity. ${ }^{10}$ Most patients presented asymptomatically ( $71 \% ; 5$ of 7 ), with anal protrusion of the distal tubing occurring in 57\% (4 of 7) of the cases. The other $29 \%$ (2 of 7) presented with right-sided abdominal pain. Our patient exhibited right-sided abdominal pain and subcutaneous emphysema. The subcutaneous emphysema raised suspicion that the tube was intraluminal, with air from the bowel tracking through the intraluminal catheter into the subcutaneous tissue. Because of this high suspicion, diagnostic evaluation proceeded from $\mathrm{CT}$ to exploratory laparoscopy.

In all cases, the abandoned distal shunt catheter penetrated a portion of the bowel. Penetration of multiple organs or the same organ multiple times occurred in $43 \%$ ( 3 of 7 ) of the cases. The pathophysiology of perforation by both intact VP shunts and retained distal peritoneal tubing has not been well established. The etiologies are categorized into 2 mechanisms: 1) acute-traumatic type, in which the initial use of a trocar for distal shunt placement contributes to perforation, and 2) chronic-irritative type, in which shunt migration and adhesion at the entry site lead to perforation of the viscus. ${ }^{10}$ In 2 of the cases reviewed, perforation of multiple organs was diagnosed at different chronological points, $, 8,8$ and in our case the small bowel was perforated multiple times. It can be deduced that movements of the distal catheter over time resulted in perforation and that acute trauma from the trocar had no role. It can therefore be inferred that in at least $43 \%$ of the cases a chronic-irritative process occurred. In addition, upon resection of the catheter and small bowel, our patient's catheter was found to have a sharp, beveled end (Fig. 3). Sharp catheter tips have been noted to increase the risk of chronic perforation,,$^{10}$ further strengthening the hypothesis that the chronic-irritative process was at play in the present case.

Management in all but 1 case involved removal of the abandoned retained distal catheter. In 57\% (4 of 7) of these cases, the tube was removed through the anus, with 2 passing spontaneously, and 2 being extracted manually. In our case, laparoscopy was the initial method of exploration, 
TABLE 1. Summary of the literature on intestinal perforation caused by shunt catheters or tubing

\begin{tabular}{|c|c|c|c|c|c|c|c|c|}
\hline $\begin{array}{c}\text { Case } \\
\text { No. }\end{array}$ & Authors \& Year & $\begin{array}{c}\text { Age at } \\
\text { Placement }\end{array}$ & $\begin{array}{l}\text { Age at } \\
\text { Dx }\end{array}$ & $\begin{array}{l}\text { Time From } \\
\text { Disconnection } \\
\text { to Dx }\end{array}$ & Presentation & Penetration & Management & Outcome \\
\hline 1 & $\begin{array}{l}\text { Ashpole et al., } \\
1995\end{array}$ & $6 \mathrm{mos}$ & $4 \mathrm{yrs}$ & $6 \mathrm{mos}$ & $\begin{array}{l}\text { Passage of catheter } \\
\text { per rectum }\end{array}$ & Bowel & Overnight observation & Asymptomatic \\
\hline 2 & Chen, 2000 & $4 \mathrm{mos}$ & 16 yrs & $12 \mathrm{yrs}$ & $\begin{array}{l}\text { Anal protrusion of } \\
\text { shunt; otherwise } \\
\text { asymptomatic }\end{array}$ & Colon & $\begin{array}{l}\text { Tube removed via colo- } \\
\text { noscopy }\end{array}$ & $\begin{array}{l}\text { Peritonitis requiring } \\
\text { colostomy; recov- } \\
\text { ered }\end{array}$ \\
\hline 3 & $\begin{array}{l}\text { O'Donoghue et } \\
\text { al., } 2002\end{array}$ & 8 yrs & 33 yrs & $<1 \mathrm{yr}$ & $\begin{array}{l}\text { Anal protrusion of } \\
\text { shunt; otherwise } \\
\text { asymptomatic }\end{array}$ & Colon & $\begin{array}{l}\text { Tube extracted per } \\
\text { anus }\end{array}$ & $\begin{array}{l}\text { Patient remained } \\
\text { asymptomatic } \\
\text { w/o complication }\end{array}$ \\
\hline 4 & $\begin{array}{l}\text { Thipphavong et } \\
\text { al., } 2004\end{array}$ & $\begin{array}{l}7 \mathrm{mos} / 10 \\
\mathrm{yrs}\end{array}$ & $12 \mathrm{yrs}$ & $4 \mathrm{mos} / 2 \mathrm{yrs}$ & $\begin{array}{l}\text { Right ab pain w/ } \\
\text { white cell count of } \\
16,300 \text { cells } / \mathrm{mm}^{3}\end{array}$ & $\begin{array}{l}\text { Liver \& ascend- } \\
\text { ing colon }\end{array}$ & $\begin{array}{l}\text { Antibiotics; spontane- } \\
\text { ous passage per } \\
\text { anus }\end{array}$ & $\begin{array}{l}\text { Recovered w/o } \\
\text { complication }\end{array}$ \\
\hline 5 & $\begin{array}{l}\text { Huang et al., } \\
2011\end{array}$ & $85 \mathrm{yrs}$ & 93 yrs & 3 yrs & $\begin{array}{l}\text { Anal protrusion of } \\
\text { shunt; otherwise } \\
\text { asymptomatic }\end{array}$ & Rectum & $\begin{array}{l}\text { Catheter removed per } \\
\text { anus w/ digital rectal } \\
\text { maneuver }\end{array}$ & $\begin{array}{r}\text { Discharged w/o } \\
\text { complication }\end{array}$ \\
\hline 6 & $\begin{array}{l}\text { Rinker et al., } \\
2013\end{array}$ & NM & 28 yrs & NM & $\begin{array}{l}\text { No local or systemic } \\
\text { symptoms related } \\
\text { to the shunt }\end{array}$ & $\begin{array}{l}\text { Gastric antrum, } \\
\text { colon, liver }\end{array}$ & $\begin{array}{l}\text { Managed conser- } \\
\text { vatively w/ serial } \\
\text { imaging }\end{array}$ & $\begin{array}{l}\text { Discharged at } \\
\text { baseline }\end{array}$ \\
\hline 7 & Present case & $<1 \mathrm{yr}$ & 14 yrs & $1 \mathrm{yr}$ & $\begin{array}{l}\text { Ab pain w/ subcuta- } \\
\text { neous emphy- } \\
\text { sema }\end{array}$ & Jejunum & Small bowel resection & $\begin{array}{l}\text { Small bowel resec- } \\
\quad \text { tion }\end{array}$ \\
\hline
\end{tabular}

$\mathrm{Ab}=$ abdominal; $\mathrm{Dx}=$ diagnosis; $\mathrm{NM}=$ not mentioned.

as there was a high suspicion for an intraluminal catheter. A laparotomy and small bowel resection were ultimately required to remove the tubing. Conservative management was used in a nonverbal asymptomatic patient and followed by serial imaging. ${ }^{5}$ A final patient had the distal tubing removed via colonoscopy, with subsequent development of peritonitis requiring a sigmoid loop colostomy with a full recovery 3 months later. ${ }^{2}$

Our review revealed a recovery rate of $100 \%$, with no associated mortality. Bowel perforation in an intact ventriculoperitoneal catheter, however, carries a morbidity of $15 \%$. The difference in mortality rate can be attributed to the nonexistent risk of meningitis with abandoned distal tubing. Undiagnosed peritonitis from bowel perforation, and its sequelae, carries a mortality rate ranging from $20 \%$ to $40 \%$. Peritonitis is a significant risk from catheter perforation of the viscus, and our review revealed the need for small bowel resection in 2 of 7 cases, constituting a significant morbidity. The rate of morbidity associated with bowel perforation from abandoned distal catheters can thus be reported as 29\% ( 2 of 7 cases). This significant morbidity illustrates the importance of weighing the risks and benefits of completely removing shunt tubing as well as considering bowel perforation in the differential diagnosis of patients with abandoned peritoneal tubing who present with abdominal pain.

This case also highlights some key factors to consider when dealing with distal catheter revisions. When performing a piecemeal shunt revision, the standard teaching is to avoid placing connectors in areas of deep soft tissues. This leads to increased difficulty with removal as well as increased mobility and a likelihood of disconnection. Our patient had a metal connector within her abdomen, which snapped and disconnected when an attempt was made to remove it from the posterior auricular incision.

The final point of consideration in this case report is the idea of weaning a VP shunt in a spinal dysraphism

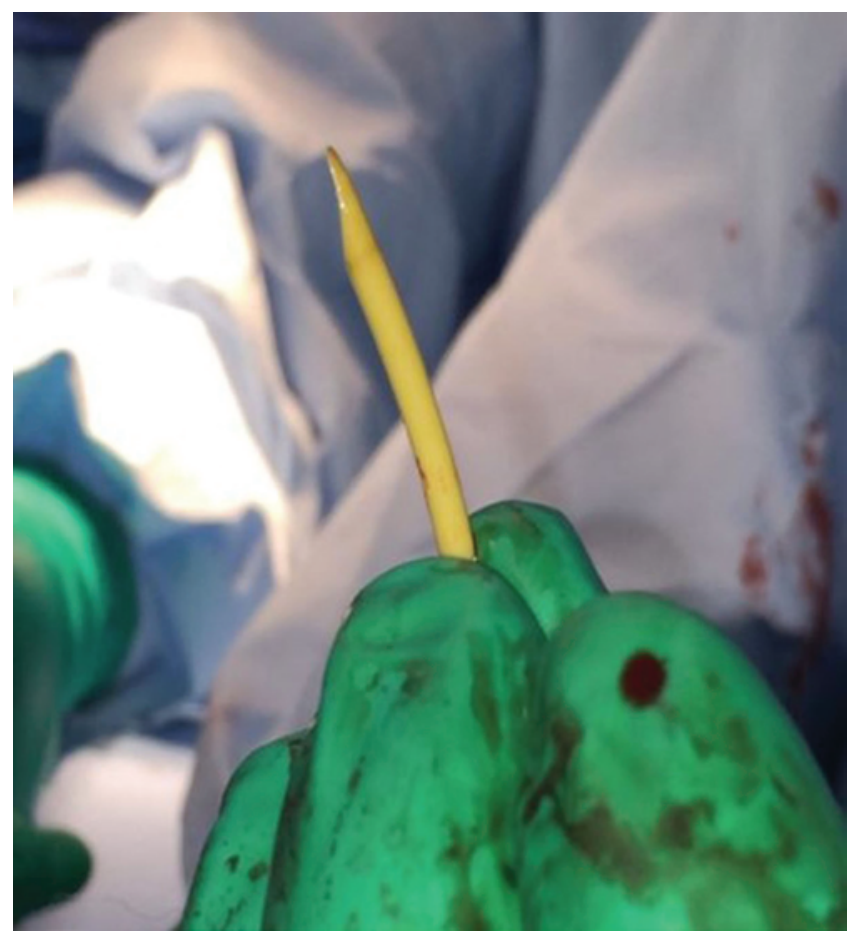

FIG. 3. Distal end of the retained VP shunt catheter with a beveled point that could have been one of the contributing factors to delayed luminal perforation. Figure is available in color online only. 
patient with shunt-treated hydrocephalus. It has been well established that patients with myelomeningocele and shunt-treated hydrocephalus require long-term CSF diversion. That being said, it is very well possible that some long-standing shunts may become occluded and cease to function. As neurosurgeons, the most difficult thing to do is distinguish these shunts from very essential shunts, such as those with very low flow but still vital function. This comes into play when children present with infection and require external CSF diversion. Attempts can be made to wean the shunt, but in the case of low flow, the adverse effects may take a significant time to be encountered. In our case, the neurosurgeons were able wean the VP shunt when placement of an external ventricular drain was required to treat the patient's infection. Our patient had been without a VP shunt for more than 12 months at the time of presentation. Appropriate follow-up should have been arranged, including delayed brain and total spine imaging to ensure that the patient would not develop delayed hydrocephalus or syringomyelia. While removing a VP shunt may seem feasible, caution should be taken and appropriate long-term follow-up performed.

\section{Conclusions}

The mortality associated with the 7 presented cases of bowel perforation secondary to retained distal peritoneal catheters was found to be nonexistent. This is in direct comparison with the $15 \%$ mortality rate seen in bowel perforation caused by intact shunt catheters. The morbidity associated with bowel perforation, however, is significantly higher and includes complications such as peritonitis and bowel resection. Given the high morbidity, clinicians need to remain vigilant in keeping bowel perforations in their differential diagnosis for patients with abandoned distal peritoneal tubing and abdominal pain.

\section{References}

1. Ashpole R, Boulton R, Holmes AE: A case of asymptomatic passage per-rectum of a fractured redundant peritoneal catheter from a ventriculo-peritoneal shunt. Eur J Pediatr Surg 5:280-281, 1995
2. Chen HS: Rectal penetration by a disconnected ventriculoperitoneal shunt tube: an unusual complication. Chang Gung Med J 23:180-184, 2000

3. Huang HM, Lee WY, Chen DC: Disconnected subduroperitoneal shunt catheter induces silent bowel perforation: An unusual complication. Int J Surg Case Rep 2:76-78, 2011

4. O’Donoghue GT, Kumar R, Taleb F, Phillips J: Per-anal extrusion of a disconnected ventriculoperitoneal catheter-an unusual complication. Ir Med J 95:88-89, 2002

5. Rinker EK, Osborn DA, Williams TR, Spizarny DL: Asymptomatic bowel perforation by abandoned ventriculoperitoneal shunt. J Radiol Case Rep 7:1-8, 2013

6. Sathyanarayana S, Wylen EL, Baskaya MK, Nanda A: Spontaneous bowel perforation after ventriculoperitoneal shunt surgery: case report and a review of 45 cases. Surg Neurol 54:388-396, 2000

7. Snow RB, Lavyne MH, Fraser RA: Colonic perforation by ventriculoperitoneal shunts. Surg Neurol 25:173-177, 1986

8. Thipphavong S, Kellenberger CJ, Rutka JT, Manson DE: Hepatic and colonic perforation by an abandoned ventriculoperitoneal shunt. Pediatr Radiol 34:750-752, 2004

9. Vinchon M, Baroncini M, Laurent T, Patrick D: Bowel perforation caused by peritoneal shunt catheters: diagnosis and treatment. Neurosurgery 58:ONS76-ONS82, 2006

10. Yılmaz N, Kiymaz N, Yılmaz C, Çaksen H, Yuca SA: Anal protrusion of ventriculo-peritoneal shunt catheter: report of two infants. J Pediatr Neurol 2:241-244, 2004

\section{Disclosures}

The authors report no conflict of interest concerning the materials or methods used in this study or the findings specified in this paper.

\section{Author Contributions}

Conception and design: Bassani. Acquisition of data: Bassani, Riccardello. Analysis and interpretation of data: Bassani. Drafting the article: all authors. Critically revising the article: Bassani, Riccardello. Reviewed submitted version of manuscript: all authors. Approved the final version of the manuscript on behalf of all authors: Bassani. Administrative/technical/material support: Bassani. Study supervision: Bassani.

\section{Correspondence}

Luigi Bassani, Department of Neurosurgery, Rutgers New Jersey Medical School, 90 Bergen St., Ste. 8100, Newark, NJ 07103. email: luigi.bassani@ rutgers.edu. 